\title{
Cytoplasmic maspin expression predicts poor prognosis of patients with soft tissue sarcomas
}

\author{
Chikako Takeda ${ }^{1,2}$, Yuzo Takagi ${ }^{1}$, Tatsushi Shiomi ${ }^{1}$, Kanae Nosaka ${ }^{1}$, Hideki Yamashita ${ }^{2}$, Mari Osaki ${ }^{2}$, Koji Endo ${ }^{2}$, \\ Takeshi Minamizaki $^{3}$, Ryota Teshima², Hideki Nagashima ${ }^{2}$ and Yoshihisa Umekita ${ }^{1 *}$
}

\begin{abstract}
Background: Maspin is a $42 \mathrm{kDa}$ protein known to act as a tumor suppressor. Although its function has not been fully elucidated, numerous reports have investigated the prognostic impact of maspin in patients with several types of cancer. However, there have been no reports on the association between maspin expression and the prognosis of patients with soft tissue sarcomas (STS). The aim of this study was thus to explore the association of maspin expression with the prognosis of patients with STS.
\end{abstract}

Methods: One-hundred and eight paraffin-embedded STS tissue samples were immunohistochemically analyzed using antibodies for maspin and Ki-67 antigen. The patients were followed up for 1 to 300 months (median: 33 months) and the prognostic value was evaluated by log-rank test and Cox's regression hazard model.

Results: Cytoplasmic maspin expression was observed in $48.1 \%$ of specimens, and was significantly correlated with a higher FNCLCC grade $(P=0.002)$ and the presence of distant metastases $(P=0.001)$, and those with cytoplasmic maspin expression had both shorter disease-free survival (DFS) and overall survival (OS) by log-rank test $(P<0.001$, $P=0.001$, respectively). By Cox's multivariate analysis, the presence of distant metastases was the only prognostic factor for DFS and OS.

Conclusions: This is the first report to reveal an association between maspin expression and the prognosis of patients with STS. Although further studies with a larger series of patients and a longer follow-up period will be needed, cytoplasmic maspin expression could be an indicator of unfavorable prognosis in patients with STS.

Virtual Slides: The virtual slide(s) for this article can be found here: http://www.diagnosticpathology.diagnomx.eu/ vs/13000_2014_205

Keywords: Maspin, Immunohistochemistry, Soft tissue sarcoma

\section{Background}

Soft tissue sarcomas (STS) are relatively rare malignant mesenchymal tumors and constitute less than $1.5 \%$ of all cancers, with an annual incidence of about 6 per 100,000 persons [1]. Except for a few types of sarcomas, histological typing does not provide sufficient information for predicting the clinical course of the disease [2]. Therefore, grading and staging systems have been used to predict prognosis and to decide on treatment strategies for adult patients with STS. Several reports have described the relationship between the grading system

\footnotetext{
* Correspondence: yume@med.tottori-u.ac.jp

'Division of Organ Pathology, Department of Pathology, Faculty of Medicine, Tottori University, 86 Nishicho, Yonago, Tottori 683-8503, Japan

Full list of author information is available at the end of the article
}

and prognosis of adult patients with STS, and it has been suggested that the histological grade is the most important prognostic factor [3,4]. In addition, the Ki-67 labeling index has also been reported to be a useful predictor for the prognosis in STS patients [5]. Maspin (mammary serine protease inhibitor) is a $42 \mathrm{kDa}$ protein known to act as a tumor suppressor, and is a member of the serine protease inhibitor (serpin) superfamily. Maspin has been shown to inhibit both tumor growth and metastasis in multiple animal models and cancer cell lines [6]. Although the function of maspin has not been fully elucidated, many reports have described the association between maspin expression and clinicopathological factors in several types of cancer such as breast, prostate, gastric, pancreatic, gallbladder, colorectal, and 
thyroid cancers, and malignant melanoma [7]. We have also reported an association between maspin expression and clinicopathological factors in several types of cancer such as breast cancer [8-10], colorectal cancer [11], endometrioid endometrial carcinoma [12] and ovarian mucinous borderline tumor [13], and have suggested that cytoplasmic maspin expression may be an indicator of poor prognosis. Although only two reports have described maspin expression in STS $[14,15]$, to our knowledge, no reports have investigated the association between maspin expression and the prognosis of patients with STS. The aim of this study was thus to investigate whether cytoplasmic maspin expression could predict the prognosis of patients with STS.

\section{Methods}

\section{Tissue specimens}

All STS tissue specimens were obtained from the Department of Pathology, Tottori University Hospital, and the affiliated teaching hospitals. We obtained 108 specimens from 108 patients who underwent surgery between October 1981 to March 2012. The specimens consisted of 94 primary tumors, 8 recurrent tumors, and 6 metastatic tumors. Information about adjuvant therapy was obtained for 99 of the patients. Neoadjuvant and/or adjuvant chemotherapy were performed in 22 patients, neoadjuvant and/or adjuvant radiotherapy in 23 patients, and both therapies in 22 patients. We also obtained clinical data such as age, gender, tumor localization, tumor size, presence of distant metastases, methods of treatment, and clinical outcome. The median follow-up period was 33 months (range: 1-300 months). A histological diagnosis was established according to the World Health Organization classification [2]. Histological grades were assigned according to the French Federation of the Cancer Center Sarcoma Group (FNCLCC) system. Written informed consent was obtained and the present study was performed with the approval of the Ethics Committee of the Faculty of Medicine, Tottori University (No. 1558).

\section{Immunohistochemical procedures}

All specimens were fixed in $10 \%$ buffered formalin and embedded in paraffin wax. After the sections $(4 \mu \mathrm{m}$ thick) were deparaffinized and endogenous peroxidase activity was blocked, they were pretreated in citrate buffer (0.01 M, pH 6.0) using a microwave oven (RE-DD6S; Sharp Corporation, Osaka, Japan) for 20 minutes. After cooling to room temperature, the sections were incubated at $4^{\circ} \mathrm{C}$ overnight with the following primary antibodies: monoclonal anti-human maspin antibody (clone EAW24; diluted 1:150; Leica Biosystems, Newcastle Ltd., UK), and mouse monoclonal anti-Ki-67 antibody (MIB-1; diluted 1:50; Dako, Glostrup, Denmark).
The sections were incubated with biotinylated anti-mouse IgG antibody (BA-2000; diluted 1:150; Vector Laboratories, Burlingame, VT) for 20 minutes, followed by streptavidin biotinylated-HRP conjugate (diluted 1:150; Invitrogen Corporation, Camarillo, CA) for 20 minutes. The sections were then incubated with $\mathrm{DAB}$ solution (Liquid DAB + Substrate, Imidazole- $\mathrm{HCl}$ buffer, $\mathrm{pH} 7.5$, containing hydrogen peroxide and an anti-microbial agent; Dako, Glostrup, Denmark) for 4 minutes, and finally counterstained with hematoxylin. Normal mammary tissue specimens were used as positive controls for maspin expression.

\section{Evaluation of immunohistochemical findings}

The cells were considered positive cells for maspin expression only when cytoplasmic staining was identified. To count the number of positive cells, a $10 \times 10$ square grid in the eye-piece was used. The sections were scanned at low and high power magnifications covering all fields. At least three areas having the highest degree of positive cells were selected, and typically 400-500 tumor cells in each field were counted irrespective of immunoreactive status. Thereafter, positive cells were counted and the positive ratio was determined. Tumors with more than $10 \%$ positive cells were considered positive for the expression of maspin. We observed Ki-67positive cell nuclei by a CCD camera in the most distinctly labeled area to evaluate Ki-67 expression. Counts were performed using high-magnification fields with the FLOVEL Image Filing System FlvFs (FLOVEL Inc., Tachikawa, Japan). For measurement of Ki-67 expression, a minimum of 1,000 tumor cells were counted, and the labeling index was determined by calculating the number of positive cells as a percentage of total cells. These evaluations were performed independently by two authors (C.T. and Y.U.) who were blinded to the patient outcome data.

\section{Statistical analysis}

Statistical analysis was performed using the Statistical Package for Social Sciences version 21 (IBM SPSS Statistics; IBM Corporation, New York, NY). The association between maspin expression and clinicopathological parameters was evaluated by non-parametric tests. The Mann-Whitney $U$ test and Chi-square test were used when there were two categorical variables of interest and the Kruskal-Wallis test when there were three variables. Survival curves were calculated using the Kaplan-Meier method and compared by the log-rank test. Multivariate analysis was performed using the Cox proportional hazards regression model and the backward selection method. Hazard ratios were reported with $95 \%$ confidence intervals (CI). Values of $P<0.05$ were considered to be statistically significant. 


\section{Results}

\section{Clinicopathological features}

Table 1 shows the characteristics of the 108 patients with STS. The majority of patients were adults, with a mean age of 58.3 years (range: $4-93$ years). 53 patients were $<60$ years, and 55 were $\geq 60$ years; 65 patients were male and 43 female. There were 29 tumors $<5 \mathrm{~cm}$ and 79 tumors were $\geq 5 \mathrm{~cm}$. There were 88 tumors located in the extremities, 18 in the trunk, and 2 in other areas. Distant metastases were absent in 71 patients and present in the remaining 37 patients. Tumors of FNCLCC grades 1,2 , and 3 were identified in 28,48 , and 32 patients, respectively. The tumors consisted of 39 leiomyosarcomas, 34 liposarcomas, 15 synovial sarcomas, 8 myxofibrosarcomas, 6 undifferentiated/unclassified sarcomas, 5 epithelioid sarcomas and 1 rhabdomyosarcoma. The 8 recurrent tumors consisted of 4 leiomyosarcomas, 2 liposarcomas, and 2 undifferentiated/unclassified sarcomas, and the 6 metastatic tumors consisted of 4 leiomyosarcomas, 1 liposarcoma, and 1 rhabdomyosarcoma.

Table 1 Association between maspin expression and clinicopathological variables in 108 soft tissue sarcomas

\begin{tabular}{|c|c|c|c|}
\hline \multirow{3}{*}{ Charactaristics } & \multicolumn{2}{|c|}{ Maspin expression } & \multirow{3}{*}{$P$-value } \\
\hline & Positive & Negative & \\
\hline & 52 cases & 56 cases & \\
\hline \multicolumn{4}{|l|}{ Age } \\
\hline$<60$ years & 21 & 32 & \multirow[t]{2}{*}{0.061} \\
\hline$\geq 60$ years & 31 & 24 & \\
\hline \multicolumn{4}{|l|}{ Gender } \\
\hline Male & 33 & 32 & \multirow[t]{2}{*}{0.318} \\
\hline Female & 19 & 24 & \\
\hline \multicolumn{4}{|l|}{ Tumor size } \\
\hline$<5 \mathrm{~cm}$ & 15 & 14 & \multirow[t]{2}{*}{0.407} \\
\hline$\geq 5 \mathrm{~cm}$ & 37 & 42 & \\
\hline \multicolumn{4}{|c|}{ Tumor localization } \\
\hline Extremity & 44 & 44 & \multirow[t]{3}{*}{0.097} \\
\hline Trunk & 6 & 12 & \\
\hline Others & 2 & 0 & \\
\hline \multicolumn{4}{|c|}{ Distant metastasis } \\
\hline Absent & 26 & 45 & \multirow[t]{2}{*}{0.001} \\
\hline Present & 26 & 11 & \\
\hline \multicolumn{4}{|l|}{ FNCLCC grade } \\
\hline 1 & 8 & 20 & \multirow[t]{3}{*}{0.002} \\
\hline 2 & 22 & 26 & \\
\hline 3 & 22 & 10 & \\
\hline \multicolumn{4}{|c|}{ Ki-67 labelling index } \\
\hline$<10 \%$ & 32 & 43 & \multirow[t]{2}{*}{0.065} \\
\hline$\geq 10 \%$ & 20 & 13 & \\
\hline
\end{tabular}

\section{Immunohistochemical findings}

The mean Ki-67 labeling index of all STS specimens was $8.76 \pm 9.77 \%$; 75 cases were labeled $<10 \%$, and 33 cases were labeled $\geq 10 \% \mathrm{Ki}-67$ positive. Maspin expression was observed only in the cytoplasm in 52 specimens, in both the cytoplasm and nucleus in 15 specimens, only in the nucleus in 11 specimens, and not at all in 30 specimens; $48.1 \%$ of STS specimens were judged to be maspin-positive. By histological type, the number and proportion of maspin positive cases were 22 (56.4\%), 8 (23.5\%), 11 (73.3\%), 2 (25.0\%), 4 (66.7\%), and 5 (100\%) for leiomyosarcoma, liposarcoma, synovial sarcoma, myxofibrosarcoma, undifferentiated/unclassified sarcoma, epithelioid sarcoma, and rhabdomyosarcoma, respectively. The details of maspin expression by histological type are shown in Table 2. Representative images of maspin staining are shown in Figure 1 for a leiomyosarcoma, liposarcoma, myxofibrosarcoma, and epithelioid sarcoma.

\section{Correlation between maspin expression and clinicopathological factors}

Cytoplasmic maspin expression was significantly correlated with distant metastases $(P=0.001)$ and FNCLCC grade $(P=0.002)$. With respect to the FNCLCC grades, a significant correlation was observed between grade 1 and grade $3(P<0.01)$. Other clinicopathological factor, including age, gender, tumor location and size, and $\mathrm{Ki}$ 67 labeling showed no significant correlation with cytoplasmic maspin expression.

Table 2 Maspin expression in 108 soft tissue sarcomas

\begin{tabular}{lll}
\hline Histologic type & \multicolumn{2}{l}{ Maspin expression } \\
\cline { 2 - 3 } & Positive (\%) & Negative \\
& $\mathbf{5 2}(\mathbf{4 8 . 1 )}$ & $\mathbf{5 6}$ \\
\hline Leiomyosarcoma & $22(56.4)$ & 17 \\
Liposarcoma & $8(23.5)$ & 26 \\
Well-differentiated & $5(29.4)$ & 12 \\
Myxoid & $2(14.3)$ & 12 \\
Pleomorphic & $1(50)$ & 1 \\
Dedifferentiated & 0 & 1 \\
Synovial sarcoma & $11(73.3)$ & 4 \\
Spindle cell & $6(85.7)$ & 1 \\
Biphasic & $5(62.5)$ & 3 \\
Myxofibrosarcoma & $2(25)$ & 6 \\
Undifferentiated/ unclassified sarcoma & $4(66.7)$ & 2 \\
Epithelioid sarcoma & $5(100)$ & 0 \\
Rhabdomyosarcoma & 0 & 1 \\
Embryonal & 0 & 1 \\
\hline
\end{tabular}



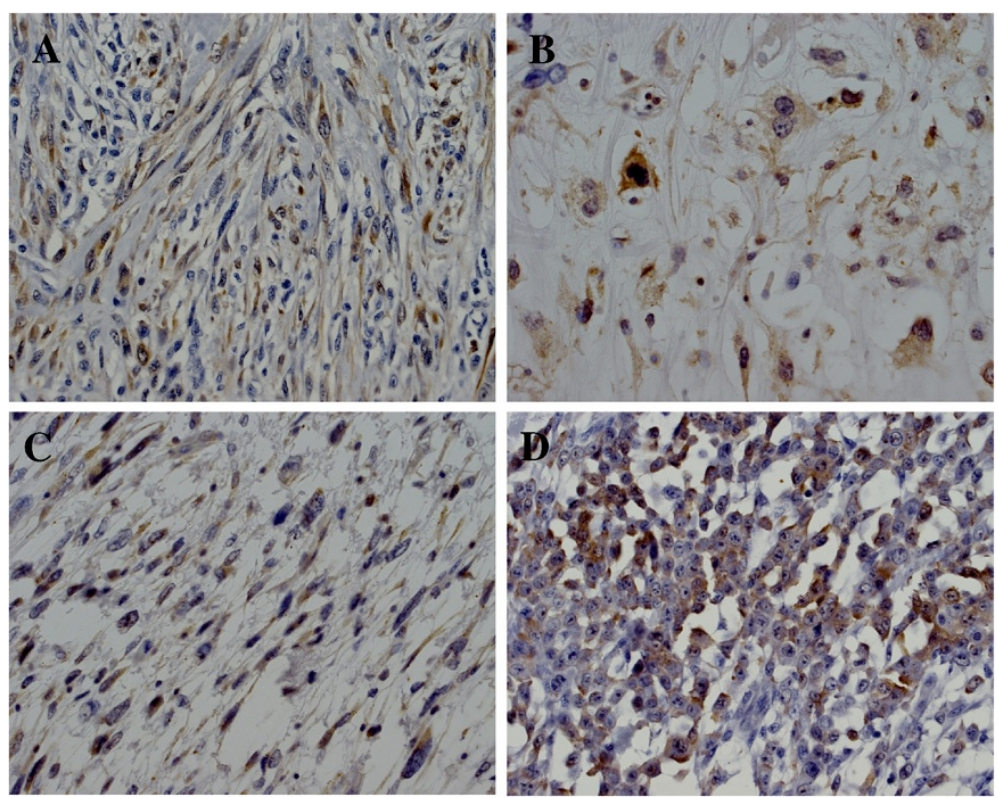

Figure 1 Representative maspin immunoreactivity in a leiomyosarcoma (A), liposarcoma (B), myxofibrosarcoma (C) and epithelioid sarcoma (D). (original magnification, $\times 400$ ).

\section{Survival analysis}

After the follow-up period, 29 patients had died of STS and 7 patients had died of other causes. Of the remaining 72 patients, 12 patients experienced recurrence of STS. We excluded 17 patients with welldifferentiated liposarcomas from the survival analysis due to their being classified as having intermediate, not malignant, tumors; of these patients, 15 were still alive and two had died of other causes. Maspin expression in only cytoplasm was observed in 47 specimens, both in cytoplasm and nucleus in 12 specimens, in only nucleus in 8 specimens, and not at all in 24 specimens. Of the 91 patients analyzed by log-rank test, the patients who were only cytoplasmic expression of maspin showed shorter overall survival (OS) and disease-free survival (DFS) $(P=0.001, P<0.001$, respectively; Figure 2$)$. Univariate analysis showed a significant difference in both DFS and OS according to FNCLCC grade $(P=0.015$, $P=0.016)$, distant metastases $(P<0.001, P<0.001)$, Ki67 labeling index $(P=0.016, P=0.031)$, and the presence of maspin expression $(P=0.013, P=0.016)$, respectively. By Cox multivariate analysis, the presence of distant metastases was the only independent prognostic indicator of both DFS and OS $(P<0.001, P<0.001$, respectively; Table 3).

\section{Discussion}

Maspin is a member of the serpin family of protease inhibitors and was originally thought to be a tumor suppressor due to its ability to inhibit invasion, motility, and metastasis of mammary tumors [16]. However, loss of maspin expression in several cancers, such as pancreatic, colorectal and ovarian cancer, is not commonly observed due to a lack of maspin expression in the corresponding normal tissue. The most compelling data regarding the clinical significance of maspin in cancer progression and metastasis emerged from survival studies of cancer patients. Although the original studies revealed an association between reduced maspin expression and cancer progression and worse prognosis, it has been demonstrated that this correlation was far more complex than originally suspected. Factors contributing to this complexity include the differences in cancer type (e.g. adenocarcinoma vs squamous cell carcinoma), cut-off values of positive criteria, antibodies used, methods of detection, and subcellular maspin distribution. The subcellular localization of maspin is predominantly cytoplasmic; however, maspin exerts its effect in the nucleus at the level of gene and chromatin regulation, and is released only as a consequence of cell damage or necrosis $[17,18]$. Goulet et al. demonstrated that nuclear localization of maspin was essential for its inhibition of tumor growth and metastasis [19]. Sood et al. reported that nuclear maspin staining was associated with increased survival, whereas cytoplasmic maspin staining was associated with a poor outcome in ovarian carcinoma [20]. Additionally, Marioni et al. reported that nuclear maspin expression was associated with a lower recurrence rate and a longer disease-free interval after surgery for squamous cell carcinoma of the larynx [21]. We have also reported that cytoplasmic maspin expression was associated with an aggressive phenotype and poor prognosis of patients with 

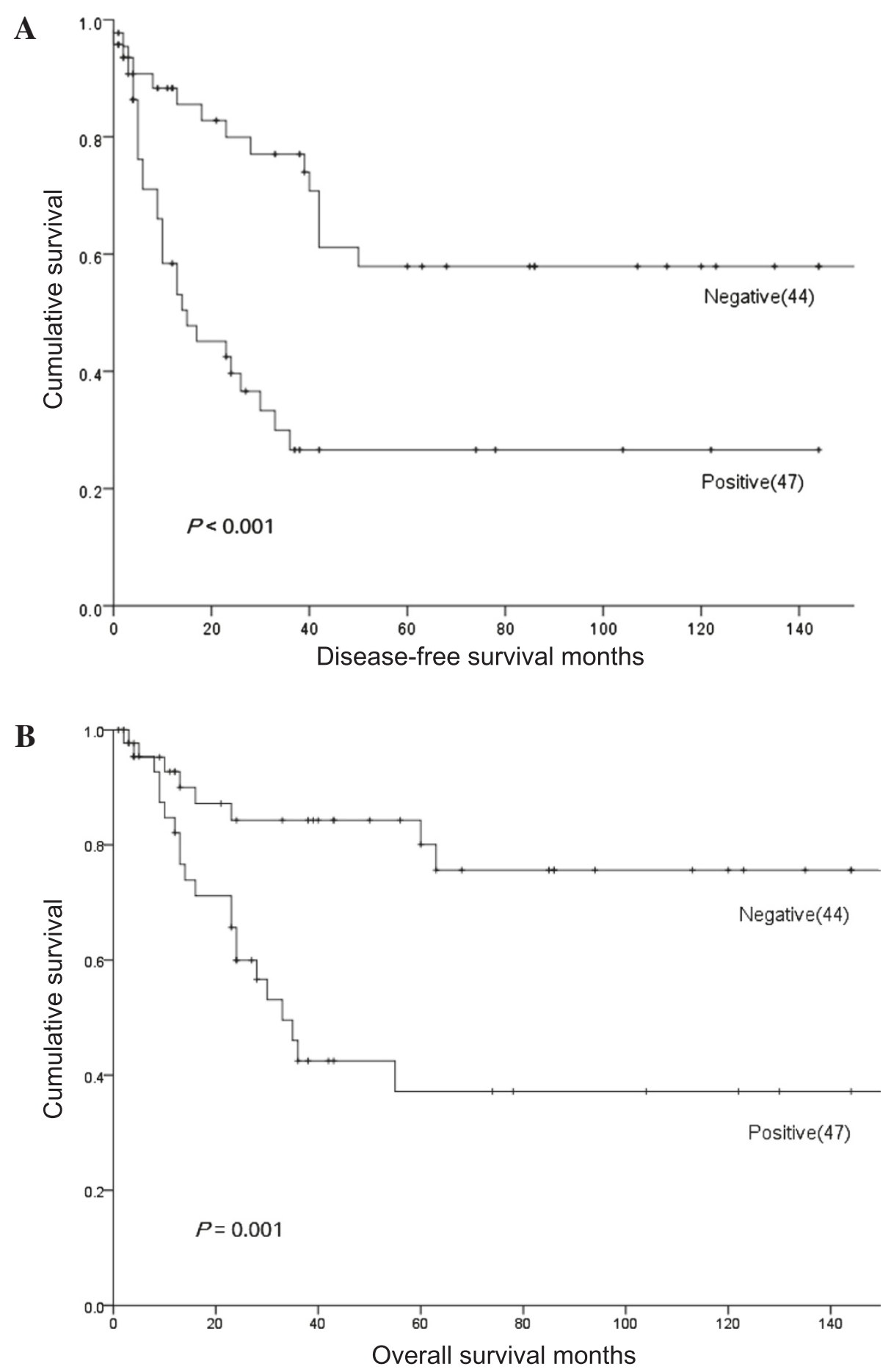

Figure 2 Disease-free survival (A) and overall survival (B) curves of 91 patients with soft tissue sarcomas according to maspin expression status.

breast cancer [8-10], colorectal cancer [11], and endometrioid endometrial carcinoma [12]. On the other hand, there have been few reports investigating maspin expression in non-epithelial tissue [22], and only two reports have described the expression of maspin in STS. Kim et al. reported a case of metastatic leiomyosarcoma from a uterus showing expression of maspin in addition to several types of growth factors, angiogenic factors, and proliferative markers in the metastatic tumor cells by immunohistochemistry and immunoblot detection [14]. Although 


\begin{tabular}{|c|c|c|c|c|c|c|}
\hline \multirow[t]{2}{*}{ Variables } & \multicolumn{4}{|c|}{ Disease-free survival } & \multicolumn{2}{|c|}{ Overall survival } \\
\hline & HR & $95 \% \mathrm{Cl}$ & $\begin{array}{l}P \text { - } \\
\text { value }\end{array}$ & $\mathrm{HR}$ & $95 \% \mathrm{Cl}$ & $\begin{array}{l}P \text { - } \\
\text { value }\end{array}$ \\
\hline \multicolumn{7}{|l|}{ FNCLCC grade } \\
\hline III vs I,II & 1.05 & $0.533-2.066$ & 0.891 & 0.82 & $0.387-1.751$ & 0.614 \\
\hline \multicolumn{7}{|l|}{ Distant metastasis } \\
\hline Present vs absent & 12.7 & $5.682-27.78$ & $<0.001$ & 55.6 & $7.575-500$ & $<0.001$ \\
\hline \multicolumn{7}{|l|}{$\begin{array}{l}\text { Ki-67 labelling } \\
\text { index }\end{array}$} \\
\hline$\geq 10 \%$ vs $<10 \%$ & 1.30 & $0.700-2.392$ & 0.410 & 1.57 & $0.754-3.286$ & 0.227 \\
\hline \multicolumn{7}{|l|}{ Maspin expression } \\
\hline $\begin{array}{l}\text { Positive vs } \\
\text { negative }\end{array}$ & 1.53 & $0.777-3.005$ & 0.219 & 1.64 & $0.708-3.791$ & 0.248 \\
\hline
\end{tabular}

HR, Hazard ratio; 95\% Cl, 95\% confidence intervals.

they did not describe the subcellular localization of maspin expression, they revealed that the maspin protein was more intensely expressed in the metastatic tumor compared to the primary uterine leiomyosarcoma. In the present study, we observed the expression of maspin in $56.4 \%$ of leiomyosarcomas. These results highlight the need for further studies on the use of maspin expression as a prognostic indicator in leiomyosarcomas. Fitzgerald et al. reported that chondrosarcoma cells exhibited upregulated maspin mRNA expression in addition to decreased DNA methylation of the maspin gene [15]. They also demonstrated that the upregulation of maspin mRNA may either play an important role in malignant progression, or simply be a biomarker of tumor progression. Their findings may support our present results that expression of maspin is correlated with the poor prognosis of patients with STS, although chondrosarcomas were not investigated in our study.

\section{Conclusion}

In conclusion, to our knowledge, this is the first report investigating the association of maspin expression with the prognosis of patients with STS. Although further studies with a larger series of patients and a longer follow-up period should be requisite, the present study suggests the potential usefulness of cytoplasmic maspin expression as a prognostic factor of patients with STS. Further carefully designed studies will be needed to elucidate the function and role of cytoplasmic maspin expression in patients with STS.

\section{Competing interests}

The authors declare that they have no competing interests.

\section{Authors' contributions}

$\mathrm{CT}$ and $\mathrm{YU}$ designed the research study and wrote the paper. $\mathrm{CT}, \mathrm{YU}, \mathrm{YT}, \mathrm{TS}$ and $\mathrm{KN}$ analyzed the data. $\mathrm{HY}, \mathrm{MO}, \mathrm{KE}$ and TM contributed essential reagents. RT and HN contributed to the proofreading of the paper. All authors read and approve the final manuscript.

\section{Acknowledgements}

We are grateful to Y. Hamamoto, K. Yamaga, H. Yoshida, N. Itaki and H. Tanaka for their excellent technical assistance.

\section{Author details}

'Division of Organ Pathology, Department of Pathology, Faculty of Medicine, Tottori University, 86 Nishicho, Yonago, Tottori 683-8503, Japan. ${ }^{2}$ Division of Orthopedic Surgery, Department of Surgery, Faculty of Medicine, Tottori University, 86 Nishicho, Yonago, Tottori 683-8503, Japan. ${ }^{3}$ Department of Orthopedic Surgery, National Hospital Organization Yonago Medical Center, 4-17-1 Kuzumo, Yonago, Tottori 683-0006, Japan.

Received: 20 August 2014 Accepted: 8 October 2014

Published online: 30 October 2014

\section{References}

1. John RG, Andrew LF, Sharon WW: Enzinger \& Weiss's Soft Tissue Tumors. 6th edition. Philadelphia: Elsevier Inc.; 2013:1-10.

2. Fletcher CDM, Bridge JA, Hogendoorn PCW, Mertens F: WHO Classification of Tumours of Soft Tissue and Bone. 4th edition. Lyon: IARC Press; 2013:14-18.

3. Costa J, Wesley RA, Glatstein E, Rosenberg SA: The grading of soft tissue sarcomas. Results of a clinicohistopathologic correlation in a series of 163 cases. Cancer 1984, 53:530-541.

4. Coindre JM: Grading of soft tissue sarcomas: review and update. Arch Pathol Lab Med 2006, 130:1448-1453.

5. Hasegawa T, Yamamoto S, Yokoyama R, Umeda T, Matsuno Y, Hirohashi S: Prognostic significance of grading and staging systems using MIB-1 score in adult patients with soft tissue sarcoma of the extremities and trunk. Cancer 2002, 95:843-851.

6. Bodenstine TM, Seftor RE, Khalkhali-Ellis Z, Seftor EA, Pemberton PA, Hendrix MJ: Maspin: molecular mechanisms and therapeutic implications. Cancer Metastasis Rev 2012, 31:529-551.

7. Berardi R, Morgese F, Onofri A, Mazzanti P, Pistelli M, Ballatore Z, Savini A, De Lisa M, Caramanti M, Rinaldi S, Pagliaretta S, Santoni M, Pierantoni C, Cascinu S: Role of maspin in cancer. Clin Transl Med 2013, 2(1):8. doi:10.1186/2001-1326-2-8.

8. Umekita $Y$, Ohi $Y$, Sagara $Y$, Yoshida $H$ : Expression of maspin predicts poor prognosis in breast cancer patients. Int J Cancer 2002, 100:452-455.

9. Umekita $\mathrm{Y}$, Yoshida $\mathrm{H}$ : Expression of maspin is up-regulated during the progression of mammary ductal carcinoma. Histopathol 2003, 42:541-545.

10. Umekita Y, Ohi Y, Souda M, Rai Y, Sagara Y, Sagara Y, Tamada S, Tanimoto A: Maspin expression is frequent and correlates with basal markers in triple-negative breast cancer. Diagn Pathol 2011, 6:36.

11. Umekita Y, Souda M, Yoshida H: Expression of maspin in colorectal cancer. In Vivo 2006, 13:317-321.

12. Tsuji T, Umekita Y, Ohi Y, Kamino M, Douchi T, Yoshida H: Maspin expression is up-regulated during the progression of endometrioid endometrial carcinoma. Histopathol 2007, 51:871-874.

13. Tsuji T, Togami S, Douchi T, Umekita Y: Difference in subcellular localization of maspin expression in ovarian mucinous borderline tumour. Histopathol 2009, 55:130-132.

14. Kim SM, Myoung H, Choung PH, Kim MJ, Lee SK, Lee JH: Metastatic leiomyosarcoma in the oral cavity: case report with protein expression profiles. J Craniomaxillofac Surg 2009, 37:454-460.

15. Fitzgerald MP, Gourronc F, Teoh MLT, Provenzano MJ, Case AJ, Martin JA, Domann FE: Human chondrosarcoma cells acquire an epithelial-like gene expression pattern via an epigenetic switch: evidence for mesenchymalepithelial transition during sarcomagenesis. Sarcoma 2011. doi:10.1155/ 2011/598218.

16. Zou Z, Anisowicz Z, Hendrix MJ, Thor A, Neveu M, Sheng S, Rafidi K, Seftor E, Sager R: Maspin, a serpin with tumor-suppressing activity in human mammary epithelial cells. Science 1994, 263:526-529.

17. Teoh SS, Whisstock JC, Bird PI: Maspin (SERPINB5) is an obligate intracellular serpin. J Biol Chem 2010, 285:10862-10869.

18. Khalkhali-Ellis Z: Maspin: the new frontier. Clin Cancer Res 2006, 12:7279-7283.

19. Goulet B, Kennette W, Ablack A, Postenka CO, Hague MN, Mymryk JS, Tuck $A B$, Giguere $V$, Chambers AF, Lewis JD: Nuclear localization of maspin is 
essential for its inhibition of tumor growth and metastasis. Lab Invest 2011, 91:1181-1187.

20. Sood AK, Fletcher MS, Gruman LM, Coffin JE, Jabbari S, Khalkhali-Ellis Z, Arbour N, Seftor EA, Hendrix MJ: The paradoxical expression of maspin in ovarian carcinoma. Clin Cancer Res 2002, 8:2924-2932.

21. Marioni G, Blandamura S, Giacomelli L, Calgaro N, Segato P, Leo G, Fischetto D, Staffieri A, de Filippis C: Nuclear expression of maspin is associated with a lower recurrence rate and a longer disease-free interval after surgery for squamous cell carcinoma of the larynx. Histopathol 2005, 46:576-582.

22. Tokuyama R, Satomura K, Maeda E, Hudoh K, Yamasaki Y, Nagayama M: Maspin is involved in bone matrix maturation by enhancing the accumulation of latent TGF- $\beta$. J Bone Miner Res 2007, 10:1581-1591.

doi:10.1186/s13000-014-0205-9

Cite this article as: Takeda et al:: Cytoplasmic maspin expression

predicts poor prognosis of patients with soft tissue sarcomas. Diagnostic Pathology 2014 19:205

\section{Submit your next manuscript to BioMed Central and take full advantage of:}

- Convenient online submission

- Thorough peer review

- No space constraints or color figure charges

- Immediate publication on acceptance

- Inclusion in PubMed, CAS, Scopus and Google Scholar

- Research which is freely available for redistribution 